\title{
Overview of ultrafine particles and human health
}

\author{
J. C. Chow \& J. G. Watson \\ Desert Research Institute, Reno, NV, USA
}

\begin{abstract}
Several hypotheses have been advanced concerning which properties of suspended particulate matter (PM) in the atmosphere cause short-term and long-term health effects. These properties include: 1) PM mass in different size fractions; 2) PM surface area; 3) PM number; 4) transition metals (especially the soluble fraction); 5) acids (especially sulfuric acid); 6) organic compounds; 7) biogenic particles; 8) sulfate and nitrate compounds (typically neutralized in whole or in part by ammonia or sodium); 9) peroxides and other free radicals that accompany and help to form PM; 10) soot (elemental carbon and associated $\mathrm{PAH}$ ); and 11) correlated cofactors (other pollutants and variations in meteorology). Particle number and surface area are dominated by ultrafine particles (UP), those with aerodynamic diameters less than $\sim 0.1 \mu \mathrm{m}$. Although the UP fraction does not contribute large quantities to $\mathrm{PM}_{2.5}$ or $\mathrm{PM}_{10}$ mass (particles with aerodynamic diameters $<2.5$ or $10 \mu \mathrm{m}$, respectively), it dominates the PM number concentration and most of its surface area. UP are produced by the condensation of hot vapors in fresh combustion emissions. They also form from natural and manmade gases as secondary aerosol by photochemical oxidation of compounds with high vapor pressures to compounds with lower vapor pressures. UP may contain transition metals, organic material, sulfuric acid, and free radicals. Owing to their small size and high mobilities, they diffuse rapidly and may combine with each other, with larger particles, and with nearby deposition surfaces. When UP are inhaled, these surfaces may include those of the upper and lower human respiratory system. Because of their short lifetimes and low mass concentrations, UP are not conveniently measured in source emissions and ambient air. For similar reasons, they are not easily generated for exposure, inhalation, and toxicological studies to determine their potential adverse effects on human health.
\end{abstract}

Keywords: ultrafine, nanoparticles, PM, health effects. 


\section{Introduction}

Several hypotheses have been advanced concerning which properties of suspended particulate matter (PM) in the atmosphere cause short-term and longterm health effects [1]. These properties include: 1) PM mass in different size fractions; 2) PM surface area; 3) PM number; 4) transition metals (especially the soluble fraction); 5) acids (especially sulphuric acid); 6) organic compounds; 7) biogenic particles; 8) sulphate and nitrate compounds (typically neutralized in whole or in part by ammonia or sodium); 9) peroxides and other free radicals that accompany and help to form PM; 10) soot (elemental carbon and associated $\mathrm{PAH}$ ); and 11) correlated cofactors (other pollutants and variations in meteorology).

Particle number and surface area are dominated by ultrafine particles (UP), those with aerodynamic diameters less than $\sim 0.1 \mu \mathrm{m}$. Although the UP fraction does not contribute large quantities to $\mathrm{PM}_{2.5}$ or $\mathrm{PM}_{10}$ mass (particles with aerodynamic diameters $<2.5$ or $10 \mu \mathrm{m}$, respectively), it dominates the PM number concentration and most of its surface area. UP are produced by condensation of hot vapours in fresh combustion emissions. They also form from natural and manmade gases as secondary aerosol by photochemical oxidation of compounds with high vapour pressures to compounds with lower vapour pressures. UP may contain transition metals, organic material, sulphuric acid, and free radicals. Owing to their small size and high mobilities, they diffuse rapidly and may combine with each other, with larger particles, and/or with nearby deposition surfaces. When UP are inhaled, these surfaces may include those of the upper and lower human respiratory system.

Because of their short lifetimes and low mass concentrations, UP are not conveniently measured in source emissions and ambient air. For similar reasons, they are not easily generated for exposure, inhalation, and toxicological studies to determine their potential adverse effects on human health. Much of what is currently known about UP and their effects on health has been discovered over the past decade.

\section{Physical and chemical characteristics of ultrafine particles}

Figure 1 represents portions of the mass particle size distribution. This is an idealized diagram that accentuates different size modes. Actual particle size and chemical measurements are not so easily classified. Relative magnitudes of the nucleation and Aitken modes are exaggerated, as these small particles dominate particle number but are a miniscule fraction of $\mathrm{PM}_{2.5}$ mass. Nucleation (or nanoparticle; $<\sim 10 \mu \mathrm{m})$ and Aitken $(10$ to $\sim 100 \mu \mathrm{m})$ modes usually overlap, and nanoparticles are often the lower size tail of the Aitken mode. UP includes both nucleation and Aitken modes.

The condensation portion of the accumulation mode forms mostly under dry conditions while the droplet mode is consistent with aqueous-phase reactions in fogs and clouds; more material accumulates within the water droplet that leaves larger particles when the water evaporates. Another interpretation of these 
modes for $\mathrm{RH}>80 \%$ is that the water-absorbing (hygroscopic) materials (e.g., sulphate and nitrate) have grown into the droplet mode while the water-repellent (hydrophobic) materials (e.g., soot and some organic carbon) have retained their original sizes. The dotted line indicates the potential for crossover among overlapping distributions; some of the coarse particles are always measured in a $\mathrm{PM}_{2.5}$ sample.

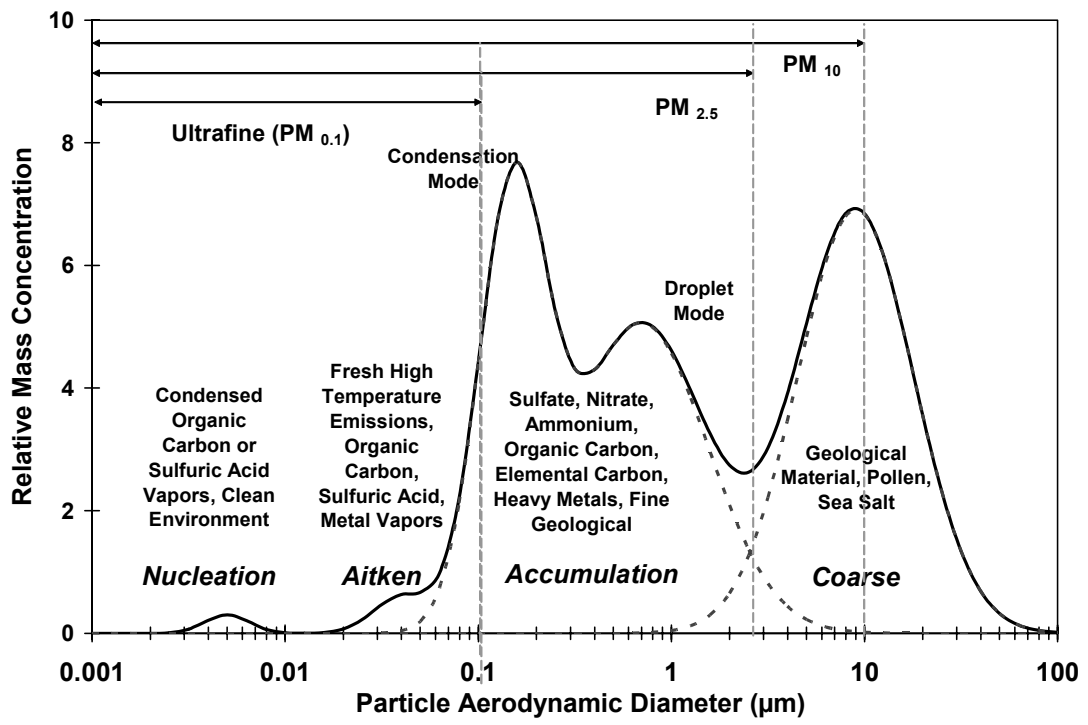

Figure 1: (After Watson, [21]). Illustration of different modes in a typical atmospheric particle size distribution. Nucleation and Aitken modes often overlap. Note that the tail (dotted line) of the accumulation mode penetrates into sizes $<0.1 \mu \mathrm{m}$, as does the coarse mode into the accumulation mode. Sources and processes that affect each mode are indicated.

Coarse particles are dominated by geological material. They may also contain sea salt near coastal areas as well as pollen and spores, plant parts, and uncontrolled industrial emissions (modern particle removal devices such as precipitators are more efficient for coarse and larger particles than they are for accumulation mode particles). Much of the accumulation mode is occupied by secondary aerosol, particles that form in the atmosphere from directly emitted sulphur dioxide $\left(\mathrm{SO}_{2}\right)$, oxides of nitrogen $\left(\mathrm{NO}_{\mathrm{x}}\right)$, ammonia $\left(\mathrm{NH}_{3}\right)$, and some of the volatile organic compounds (VOC, especially aromatics from internal combustion engines and terpenes and sesquiterpenes from vegetation).

Figure 2 compares the particle number and surface area for a $1 \mu \mathrm{g} / \mathrm{m}^{3}$ concentration at different size intervals. Each $0.5 \mu \mathrm{m}$ diameter particle in the accumulation mode would require one thousand $0.05 \mu \mathrm{m}$ or one million 0.005 $\mu \mathrm{m}$ diameter particles in the ultrafine mode to account for the same mass 
concentration. By the same token, the $0.005 \mu \mathrm{m}$ particle has 10,000 times the surface area as the $0.5 \mu \mathrm{m}$ particle. If adverse health effects correspond to the number or contact area of particles rather than their total mass, then UP may have a large effect despite their low mass concentrations. For practical purposes, $\mathrm{PM}_{2.5}$ is a good indicator for the accumulation mode while the difference between $\mathrm{PM}_{10}$ and $\mathrm{PM}_{2.5}$ is a good indicator of the coarse mode. UP is usually within the noise of these commonly measured mass fractions and is typically reported as particle number.

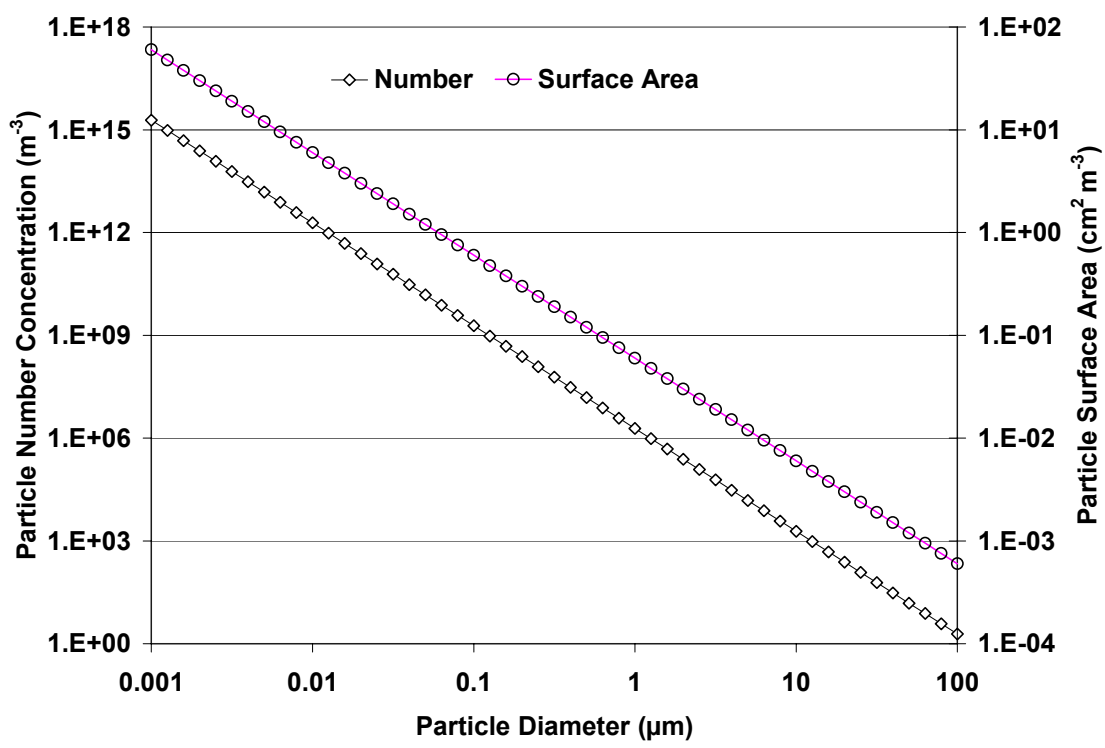

Figure 2: Particle number and surface area corresponding to a $1 \mu \mathrm{g} / \mathrm{m}^{3}$ concentration for unit density particles as a function of geometric particle diameter.

UP are both directly emitted by combustion sources and can form in the atmosphere. Coal, petroleum products (residual oil, diesel [including fuel oil, kerosene, and aircraft fuel], and gasoline being the most common), and hydrocarbon gases (mostly methane, but also including propane and butane) are in most common use by internal and external combustion processes. Fossil fuels often include trace amounts of sulphur that can oxidize to sulphuric acid. As organic gases and sulphuric acid cool upon dilution with ambient air, they may condense onto larger particles or nucleate into UP. Black carbon soot is produced by incomplete combustion in oxygen-starved combustion. Some of these may be UP, but they often grow due to condensation and adsorption of vapours or collide with and collect the UP nuclei.

UP are also produced in clean environments. Gaseous hydrocarbons (HC) emitted by natural (e.g., plant life, wildfire) and anthropogenic (e.g., fossil fuel 
and biofuel combustion) sources transform into heavier $\mathrm{HC}$ and oxygenated semi-volatile organic compounds (SVOC) with lower vapour pressures in the presence of sunlight. These gases can nucleate when their vapour pressure exceeds the saturation vapour pressure at a given temperature. This nucleation usually occurs when PM mass concentrations are low, as the vapours preferentially condense on larger particles when they are available in sufficient quantities. The nucleation mode usually occurs in clean atmospheres but also has been recently observed in urban areas. UP are often found in fresh combustion emissions, but they rapidly combine with each other and larger accumulationmode particles.

Several competing and complementary processes cause UP number concentrations to decrease, and their sizes to increase, with aging time:

- Nucleation: When the atmosphere is supersaturated with a gas, spontaneous nucleation of small particles with $\sim 1 \mathrm{~nm}$ diameter occurs. This dominates mostly in clean environments, as condensation onto existing particles is favoured in more polluted environments.

- Condensation and evaporation: When the ambient vapour pressure is higher than the saturation vapour pressure, condensation occurs and particles are formed or grow to larger sizes. Saturation pressures are larger over very small particles ( $>5$ to $10 \mathrm{~nm}$ ) than they are over larger particles owing to their curvature (Kelvin effect), so condensation is favoured on larger particles and evaporation is favoured on smaller particles. Evaporation occurs with increasing temperature and with dilution of the gaseous precursors below the saturation vapour pressure. Owing to the Kelvin effect, small particles may evaporate with their vapours condensing on larger particles, thereby leading to growth.

- Coagulation: Particles collide and combine with each other when concentrations area high, thereby decreasing their number and increasing their size.

- Deposition: Particle diffuse and adhere to the ground or other surfaces that they encounter. They can also be intercepted by clouds and fogs with ultimate rainout.

\section{Ultrafine particle measurement methods}

UP can be measured with respect to number, surface area, particle volume or particle mass. Continuous or semi-continuous direct reading methods include: 1) condensation particle counters, 2) electrostatic classifiers with condensation particle counters; 3) electronic low pressure impactors; and 4) particle mass spectrometers. These instruments can obtain number counts, size distributions, and even some chemical concentrations over averaging periods of seconds to minutes. Other methods acquire samples on substrates that are taken on filters or substrates and returned to the laboratory for mass measurements and other chemical analyses. Electron microscopy quantifies particle sizes and shapes on filter samples that have not necessarily been preceded by a size selective inlet. 


\section{Ultrafine concentrations and exposures}

UP number concentrations and size distributions are highly dynamic. As such, cumulative human exposure will depend on the amount of time that an individual spends in areas with high and low concentrations. The transient nature of UP also has important implications for selection of an indicator that can be monitored to determine safe concentration levels. $\mathrm{PM}_{10}$ and $\mathrm{PM}_{2.5}$ mass concentrations are currently used as health indicators in the United States because they are practical to measure, show a reasonable spatial homogeneity, and have been epidemiologically related to health effects.

Naturally occurring UP concentrations are measured near natural sources and at global- and continental-scale monitoring sites and from aircraft. Particle number counts are often in the range of 4,000 to $20,000 \mathrm{~cm}^{-3}$, often comparable to the numbers measured in cities. Particle sizes are often lower. UP particle bursts in the nucleation model ( 3 to $10 \mathrm{~nm}$ ) have been found frequently in coastal areas and in aircraft measurements above clouds. It is speculated that clouds reflect some of the solar radiation, thereby increasing the photochemical activity and oxidation of trace sulphur compounds that condense to small particles. Number counts of $100,000 \mathrm{~cm}^{-3}$ have been reached in these pristine environments under these conditions.

At the other extreme, UP have been measured in the plumes emitted by combustion sources In-plume concentrations are often within the range of $10^{6}$ to $10^{9} \mathrm{~cm}^{-3}$ and depend on combustion conditions and cooling. Number concentrations change with the sampling method, especially the extent of dilution and cooling. Cooling tends to create new particles by condensation, but dilution with clean air that accompanies dilution often reduces vapour pressures of condensable gases so that they do not nucleate. UP numbers are higher in plumes that have lower $\mathrm{PM}_{2.5}$ mass emissions, as UP tend to collect on the larger accumulation mode particles, and condensable vapours favour the larger particles over homogeneous nucleation. For this reason it is difficult, and possibly even meaningless, to obtain UP emission factors for combustion sources. Variability in the emissions testing methods could result in orders of magnitude changes in the number of particles emitted per unit of fuel consumed.

People usually avoid breathing direct emissions from exhaust plumes, but they often are exposed to slightly aged plumes, especially while walking along roadways, waiting for public transportation, or even at homes and workplaces located near major traffic corridors. Much emphasis has been placed on measuring concentrations and determining human exposures at different distances from heavily-trafficked highways UP concentrations decrease more rapidly than larger particles with distance from heavily-traveled roadways.

Much of human exposure takes place indoors, at home, in school, or at the workplace and UP numbers that equal or exceed outdoor concentrations are often found in these environments. Some of the outdoor UP infiltrates inside, but there are a large number of indoor emitters. Vacuum cleaner exhaust [2] contained $\sim 10^{4} \mathrm{~cm}^{-3}$ of UP that could be reduced by three orders of magnitude by adding a HEPA filter. Fogarty and Nelson [3] report indoor UP numbers approaching 
$10^{5} \mathrm{~cm}^{-3}$ near laser printers, photocopiers, vacuum cleaners, cleaning supplies, and tobacco smoke. These far exceed number counts in garages with vehicle exhaust where concentrations are $\sim 20,000 \mathrm{~cm}^{-3}$. Measurements near furnace leaks and chimney cracks were as high as $500,000 \mathrm{~cm}^{-3}$. Rundell [4] found increases from $10,000 \mathrm{~cm}^{-3}$ to more than $250,000 \mathrm{~cm}^{-3}$ when ice was resurfaced in ice-rinks. Surfacing machines powered by propane yielded slightly higher concentrations than gasoline powered machines.

Normal household concentrations average $\sim 10,000 \mathrm{~cm}^{-3}$ [5], with hospital concentrations about half this [6]. Cooking with gas can cause UP numbers to rise two or threefold indoors, but numbers decrease and size increases within minutes after emission [7]. Episodic and long-term measurements have been found at urban-scale sites that range in number from those found at pristine areas to those found at roadside monitors. Typical urban-scale concentrations are in the range of 5000 to $20,000 \mathrm{~cm}^{-3}$, but they are highly variable in space and time. Values vary substantially owing to the different types of measurements applied and the proximity of the monitors to nearby emissions. There is nearly always a morning traffic peak with large numbers and small size distributions during the morning. Sometimes short-duration peaks in number and smaller sizes are observed when an elevated plume mixes to the surface in the afternoon. These events are usually of short duration. Of more recent interest is a banana-shaped afternoon increase in number and size with time. This was previously thought to be a regional-scale phenomenon because urban areas were believed to provide too many existing particles to create many new particles by nucleation. These photochemical mechanisms have been found in several urban areas and appear to provide a mechanism for a more widespread exposure than the transport of plumes from nearby sources.

\section{Inhalation and dosage}

Suspended particles must be inhaled and deposited in different parts of the human body to cause adverse health effects. Dosage refers to the quantity that is not exhaled and remains in different parts of the body. Figure 3 shows approximately how much of different particle sizes deposit in different parts of the human respiratory system. The extra thoracic region consists of the nasal, oral, pharyngeal and laryngeal airways. The main mechanisms for deposition in this region are impaction and diffusion. Most particles in the coarse particle fraction are removed by impaction in this upper part of the respiratory system. Allergic reactions and sinus ailments result from irritation in this region. The intrathoracic region includes the trachea, bronchial airways and alveoli in the lung. Particles reaching this region can cause lung damage and potentially transfer to the bloodstream for transport to other organs. Most of the UP pass through the upper respiratory tract and deposit in the lower respiratory tract. Deposition efficiencies increase at higher breathing rates, such as those experienced during exercise.

Inhalation models are of varying complexity, with many simplifying assumptions that limit their accuracy and precision, especially for UP. Most include the particle deposition mechanisms of impaction, interception and 
diffusion. The complex twists and turns of the upper and lower airways are usually simplified to straight pipes with sharp bends. Constant temperatures and relative humidities are assumed throughout the airway. Condensation, evaporation, hygroscopic properties, and particle agglomeration are omitted.

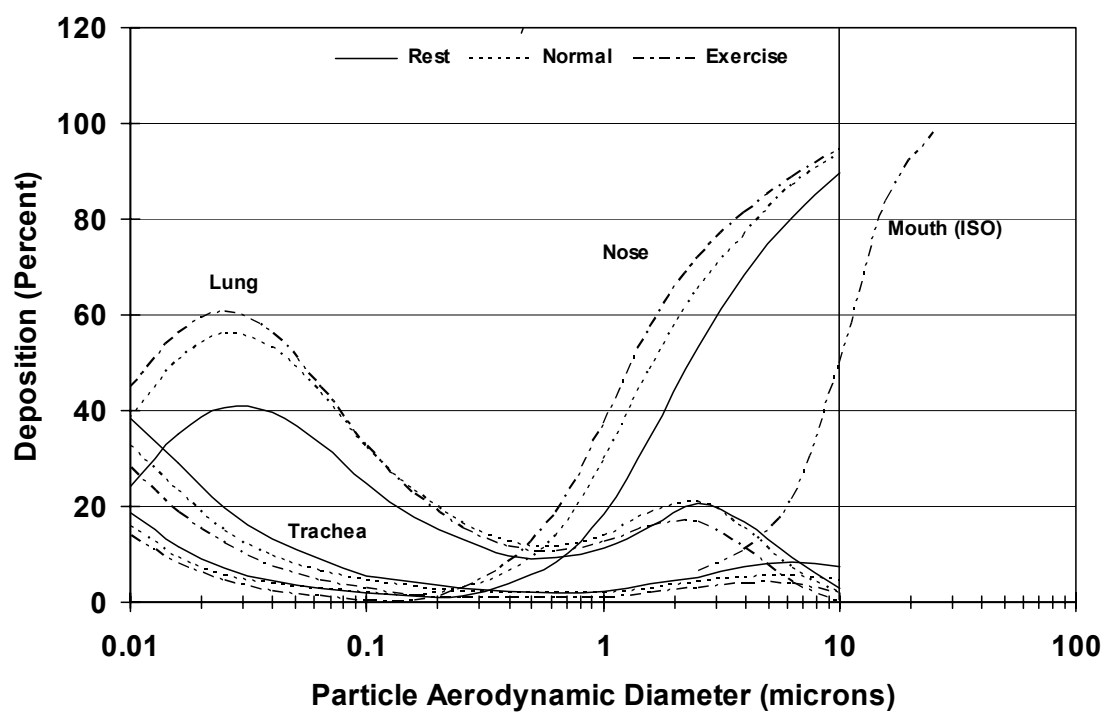

Figure 3: (From Chow, [22]). Ultrafine and larger particle deposition in different portions of the human respiratory tract, based on Phalen et al. [23].

Zhang et al. [8] describe a computational fluid dynamic (CFD) approach to inhalation and deposition modelling that includes many, but not all of these variables. Upper airway and lung bifurcation airways are modelled separately, with the end conditions of the upper airway model serving as initial conditions for the lower airway model. Total dosage is measured by having human subjects inhale particles of known sizes through a mouthpiece with a nose plug, then measuring the concentrations and sizes when the subject exhales. The difference between inhaled and exhaled as a function of size is taken at that which remained within the body. Some deposited material may be dislodged and exhaled in subsequent breathing cycles, but this averages out over multiple cycles. Tests are made with subjects at rest and under respiratory stress, as well as on subjects with different ages and physical characteristics. There is substantial variability among subjects.

\section{Toxicology}

Air pollution toxicology studies determine the extent to which the human body reacts adversely to physical, chemical, and biological irritations caused by inhaled particles and gases. Toxicological studies are conducted in vivo, 
wherein living subjects inhale UP, or in vitro, wherein UP is applied to cell cultures.

Toxicological studies are usually performed by trained physicians and the terminology differs from that used by air quality scientists and engineers. Several commonly-used terms are defined below to facilitate understanding of the published literature.

- Biopersistence [9]: A measure of particle retention in in vivo studies.

- Biodurability [9]: A measure of particle retention in in vitro studies.

- Clearance [10]: Removal of non-soluble particles from the lung via the airways or via the pulmonary interstitium/lymphatic system.

- Cytokine: An intercellular chemical messenger protein released by white blood cells. Cytokines facilitate communication among immune system cells and between immune system cells and the rest of the body.

- Epithelium: The cells or membrane covering the outside of organs.

- Fibroblast: A cell from which connective tissue develops

- Fibrosis: A process producing scar tissue that forms as a reaction to injury or during a healing process.

- Growth factors: Small proteins produced by the human body that enable cells to communicate and effectively coordinate activities between one another. Growth factors in the body affect the individual cells by binding to growth-factor-specific receptors on the cell surface. A specific growth factor may have many cell sources and can use different signal transduction pathways at different times and with different cells. Growth factors are involved in complex feedback loops between the immune, nervous and endocrine systems, and have significant effects on DNA, RNA, protein synthesis, and cell division.

- Lavage: Washing lung surfaces to obtain cells and foreign materials. Usually performed multiple times with a saline solution. Lavage is applied to both live and sacrificed subjects as well as to cell cultures. Lavage contents are analyzed chemically and microscopically.

- Macrophage: A white blood cell that engulfs and digests foreign organisms. Macrophages also stimulate helper T-cells to participate in the immune system response.

- Neutrophil: A type of white blood cell distinguished by a lobed nucleus and granular cytoplasm. It is capable of ingesting and killing bacteria and releases various substances, such as lysozyme (antibacterial enzyme) and oxidizing agents.

- Phagocyte: A cell that is able to engulf and break down foreign particles, cell debris and disease producing micro-organisms in the body. Phagocytes form an important part of the natural defense mechanism in most animals.

- Proteases: Enzymes that cause the decomposition of protein.

- Retained dose [9]: The amount of inhaled particles that remain after clearance mechanisms have reduced the initial dose. 
Macrophages, neutrophils, and phagocytes from the lung obtained by lavage are often analyzed with respect to type and number to determine the extent to which a toxicological effect has been observed. Chemicals released by neutrophils and growth factors are often measured as indicators of the functioning of the body's immune system. Very high dosages are given during some tests to determine when the body's defence mechanisms are overwhelmed.

Several hypotheses have been advanced about the toxicological effects of UP and why they might be more intense than those of larger particles [11-13]:

1. UP are more inflammatory than larger particles. The larger UP surface area reacts with macrophages and epithelial cells that prime and activate cells for inflammatory reactions.

2. UP contain more or release more toxic free radicals from their surfaces.

3. UP are not phagocytized by alveolar macrophages as efficiently as larger particles. Much larger UP numbers may spread more widely over the alveolar epithelium, thereby creating a smaller signal to the macrophages than the less numerous, and more spatially distinct, larger particles.

4. UP inhibit phagocytosis, the ability of phagcytes to remove foreign objects.

5. UP translocate from their initial deposition position to other locations. Insoluble UP may translocate from the lungs to other organs through the bloodstream or lypmphatic system.

6. Adverse UP effects are enhanced in the presence of oxidant gases (e.g., ozone).

7. Older people and those with compromised respiratory tracts are more susceptible to UP than to larger particles.

Organic chemicals (e.g., polycyclic aromatic hydrocarbons, PAH) can affect the DNA, causing mutations that may result in cancerous tumours. These are relatively long-term effects that require consistent exposure. The larger number of UP provides a larger probability of interaction with cells and the larger surface area gives more opportunity for irritation and interaction with the DNA. Soluble transition metals can generate hydroxyl radicals which are highly reactive and cause neutrophils to release inflammatory mediators. Plaques may form and cells may rupture as a result of this inflammation. Aveolar machrophages and neutrophils may be activated on ingesting UP, thereby releasing cytokines. These can cause fibrosis in several of the body's organs.

Under good conditions, alveolar macrophages will ingest and clear UP from the deep lung. However, these may become saturated in the brochoalveolar space and adhere or pass through the epithelium. Upon passage, their secretions can become incorporated into the capillary and lymphatic systems, and these secretions may cause fibrosis in other organs. When macrophages are overwhelmed, UP may directly contact, remain on, and even pass through the epithelium. Some of the non-soluble UP may enter the bloodstream and become lodged in other organs such as the heart. 
Most toxicological studies have been performed on rodents, notably rats, mice, hamsters, and guinea pigs. Dogs have also been used in limited studies. A few studies have involved a limited number of human subjects. The advantage of using animals is that they can be subjected to much higher, more frequent, and longer UP exposures than would be ethically acceptable or practical for humans. Animals can also be sacrificed after exposure to obtain a wider range of measurements than are possible for human subjects. Animal subjects are also less costly to recruit and maintain. UP and other pollutant concentrations can be delivered intertracheally to animals, thereby bypassing deposition in the upper respiratory tract and providing a better estimate of dosage deep into the lung. The disadvantage of animals is that their inhalation and physiological reaction properties differ substantially form those of humans. The chemical and physical mechanisms may be similar in animals and humans, but the dosage that causes an effect is quite different.

A large number of different UP test aerosols have been generated for toxicological testing. Titanium dioxide $\left(\mathrm{TiO}_{2}\right)$ is a solid powder that can be obtained in with sizes in the UP and accumulation modes and can be suspended and dispersed for presentation to the subjects. Elemental carbon (EC) can be reliably produced with electric spark generators. Carbon black is another solid powder that is available in different sizes and has a more complex structure than the EC produced by carbon electrodes. Interest in the effects of metals has led to tests with aluminum, cadmium, cobalt, copper, gallium, nickel, and zinc compounds. Teflon fumes are also used. With the advent of aerosol concentrating inlets described in Section 3, it has become possible to expose subjects to concentrated air pollutants.

A large number of health end-points can be measured. Most of these are determined chemically or by growth cultures after the subjects are sacrificed. Counting of macrophages, neutrophils, and phagoscytes in lavage solutions is most commonly used. There are usually many more macrophages after UP exposure, indicating that the body is attempting to clear the inhaled UP. Alveolar macrophages constitute the main UP clearance mechanism. Substantial and consistent overload is needed before other adverse effects are incurred [14]. This is probably why very large UP concentrations are needed to overwhelm these mechanisms, or they must be already weakened by compromising the test subjects.

\section{Epidemiology}

Epidemiological studies seek relationships between health end-points such as respiratory illness (morbidity) or death (mortality) and air quality indicators such as $\mathrm{PM}_{2.5}$ and $\mathrm{PM}_{10}$ mass, gaseous pollutant concentrations, and UP number concentrations. Other end-points are: 1) peak respiratory flow (PEF) as measured with a flow meter is a common end-point, 2) chronic obstructive pulmonary disorder (COPD), 3) frequency and intensity of medication use, and 4 ) increases in respiratory symptoms such as stuffiness or cough.

A small number of epidemiological studies have been undertaken to relate UP concentrations to adverse affects [11, 15-19]. 
Cities with epidemiological studies include Koupio and Helsinki Finland, Erfurt Germany, Aberdeen Scotland, Amsterdam Netherlands, and Linz Austria. All of these identified vehicle exhaust as a common source of several pollutants, including UP. $\mathrm{PM}_{2.5}$ or $\mathrm{PM}_{10}$ mass were also included in most of the analyses, as were soot (usually approximated from British Smoke [BS] or elemental carbon $[\mathrm{EC}])$, oxides of nitrogen $\left(\mathrm{NO}, \mathrm{NO}_{2}\right)$, sulfur dioxide $\left(\mathrm{SO}_{2}\right)$ and carbon monoxide (CO). In some cases, chemical composition was measured on 24-hour average filters using a Harvard Impactor Sampler, but this speciation did not apply to UP. Different regression models were applied to the multivariate ambient concentrations and health end-points to determine the contributions of different pollutants to health.

Most of these studies found consistency with previous epidemiological studies [20] in that health indicators showed more distress as pollution levels increased. No associations of adverse health effects were exclusively attributable to UP, although some of the regression models explained more of the variance in end-points when UP number was included as a variable. Several of the studies noted a good correlation between UP number and $\mathrm{PM}_{2.5}$ that would make their isolated effects collinear with each other.

\section{Summary and conclusions}

UP represent a small fraction of the particle mass, but dominate particle number and surface areas. UP number can be quantified with condensation particle counters. UP size distributions can be measured with scanning electrical mobility analyzers, low pressure impactors, and single particle mass spectrometers. Different instruments give different number counts and size distributions owing to different particle properties and size ranges measured. UP derive from fresh combustion emissions, typically combustion sources, as well as nucleation of oxidized gases. UP have natural as well as manmade origins.

UP are short-lived, on the order of minutes to hours, owing to evaporation and coagulation with other particles. UP last longer in clean remote environments than in polluted urban environments where condensation is preferred on existing larger particles. UP number counts are highly variable with space and time. Background UP concentrations are typically 5000 to 20,000 $\mathrm{cm}^{-3}$, but they can approach $10^{5} \mathrm{~cm}^{-3}$ during nucleation events. Urban concentrations are typically 10,000 to 50,000 , with highest concentrations measured near roadways. Nucleation events have recently been observed in urban environments.

UP deposit less in the upper respiratory tract and more in the deep lungs than do larger particles. Higher numbers increase the probability of contact with lung tissue and transport across the lung epithelium into the interstitium. Toxicological studies, mostly with animal subjects, produce larger measurable health end-points for UP than for equal masses of accumulation mode particles in compromised subjects. However, test aerosols are usually at higher concentrations than ambient and compositions are not typical of those in ambient air. Toxicological studies indicate that UP can be highly oxidizing, thereby 
inducing inflammation in macrophages and lung tissues. Very high concentrations can overwhelm the macrophage removal system, especially when subjects are compromise.

Epidemiological studies relating UP to health effects are few. UP is highly correlated with other pollutants and the relative risk it provides is not clearly distinguishable from that associated with large sizes fractions such as $\mathrm{PM}_{2.5}$ and $\mathrm{PM}_{10}$. Time lagged regression for a study in Germany showed respiratory effects one day after exposure and cardiovascular effects four days after exposure.

\section{References}

[1] Mauderly, J.L., Neas, L.M., \& Schlesinger, R.B., PM monitoring needs related to health effects. Atmospheric Observations: Helping Build the Scientific Basis for Decisions Related to Airborne Particulate Matter, eds. D.L. Albritton \& D.S. Greenbaum, Health Effects Research Institute: Cambridge, MA, pp. 9-14, 1998.

[2] Lioy, P.J., Wainman, T., Zhang, J., \& Goldsmith, S., Typical household vacuum cleaners: The collection efficiency and emissions characteristics for fine particles. J.Air Waste Manage.Assoc., 49(2), pp. 200-206, 1999.

[3] Fogarty, R. \& Nelson, P.A., Tracking ultrafine particles in building investigations. Indoor Air Quality Handbook, eds. J.D. Spengler, J.M. Samet, \& J.F. McCarthy, McGraw-Hill: New York, p. 50.1-50.18, 2001.

[4] Rundell, K.W., High levels of airborne ultrafine and fine particulate matter in indoor ice arenas. Inhal.Toxicol., 15(3), pp. 237-250, 2003.

[5] Wallace, L. \& Howard-Reed, C., Continuous monitoring of ultrafine, fine, and coarse particles in a residence for 18 months in 1999-2000. J.Air Waste Manage.Assoc., 52(7), pp. 828-844, 2002.

[6] Riesenfeld, E., Chalupa, D., Gibb, F.R., Oberdörster, G., Gelein, R., Morrow, P.E., Utell, M.J., \& Frampton, M.W., Ultrafine particle concentrations in a hospital. Inhal.Toxicol., 12(Suppl 2), pp. 83-94, 2000.

[7] Dennekamp, M., Howarth, S., Dick, C.A., Cherrie, J.W., Donaldson, K., \& Seaton, A., Ultrafine particles and nitrogen oxides generated by gas and electric cooking. Occup.Environ.Med., 58(8), pp. 511-516, 2001.

[8] Zhang, Z., Kleinstreuer, C., Kim, C.S., \& Cheng, Y.S., Vaporizing microdroplet inhalation, transport, and deposition in a human upper airway model. Aerosol Sci.Technol., 38pp. 36-49, 2004.

[9] Oberdörster, G., Ferin, J., Soderholm, S.C., Gelein, R., Cox, C., Baggs, R., \& Morrow, P.E., Increased pulmonary toxicity of inhaled ultrafine particles: Due to lung overload alone? Ann.Occup.Hyg., 38(Suppl. 1), pp. 295-302, 1994.

[10] Ferin, J., Pulmonary retention and clearance of particles. Toxicol.Lett., 72(1-3), pp. 121-125, 1994.

[11] Ibald-Mulli, A., Wichmann, H.E., Kreyling, W., \& Peters, A., Epidemiological evidence on health effects of ultrafine particles. J.Aerosol Med., 15(2), pp. 189-201, 2002. 
[12] MacNee, W. \& Donaldson, K., How can ultrafine particles be responsible for increased mortality? Monaldi Arch.Chest Dis., 55(2), pp. 135-139, 2000 .

[13] Oberdörster, G., Toxicology of ultrafine particles: In vivo studies. Phil.Trans.Roy.Soc.Lond.A, 358(1775), pp. 2719-2740, 2000.

[14] Ferin, J., Oberdörster, G., \& Penney, D.P., Pulmonary retention of ultrafine and fine particles in rats. Am.J.Respir.Cell Mol.Biol., 6(5), pp. 535-542, 1992.

[15] Pekkanen, J., Peters, A., Hoek, G., Tiittanen, P., Brunekreef, B., de Hartog, J., Heinrich, J., Ibald-Mulli, A., Kreyling, W.G., Lanki, T., Timonen, K.L., \& Vanninen, E., Particulate air pollution and risk of STsegment depression during repeated submaximal exercise tests among subjects with coronary heart disease - The exposure and risk assessment for fine and ultrafine particles in ambient air (ULTRA) study. Circulation, 106(8), pp. 933-938, 2002.

[16] Peters, A., Wichmann, H.E., Tuch, T., Heinrich, J., \& Heyder, J., Respiratory effects are associated with the number of ultra-fine particles. Am.J.Respir.Crit.Care Med., 155(4), pp. 1376-1383, 1997.

[17] Spix, C., Tuch, T., \& Wichmann, H.E., Daily mortality and fine and ultrafine particulates in Erfurt, East Germany. p. 35, 1996.

[18] von Klot, S., Woelke, G., \& Tuch, T., Short-term effects of ultrafine and fine particles on medication use in asthmatic adults. Am.J.Respir.Crit Care Med., 161p. A310, 2000.

[19] von Klot, S., Wolke, G., Tuch, T., Heinrich, J., Dockery, D.W., Schwartz, J., Kreyling, W.G., Wichmann, H.E., \& Peters, A., Increased asthma medication use in association with ambient fine and ultrafine particles. Eur.Respir.J., 20(3), pp. 691-702, 2002.

[20] Pope, C.A., III, Dockery, D.W., \& Schwartz, J., Review of epidemiological evidence of health effects of particulate air pollution. Inhal.Toxicol., 7(1), pp. 1-18, 1995.

[21] Watson, J.G., Visibility: Science and regulation. J.Air Waste Manage.Assoc., 52(6), pp. 628-713, 2002.

[22] Chow, J.C., Critical review: Measurement methods to determine compliance with ambient air quality standards for suspended particles. J.Air Waste Manage.Assoc., 45(5), pp. 320-382, 1995.

[23] Phalen, R.F., Cuddihy, R.G., Fisher, G.L., Moss, O.R., Schlessinger, R.B., Swift, D.L., \& Yeh, H.C., Main features of the proposed NCRP Respiratory Tract Model. Radiat.Protect.Dosim., 38(1/3), pp. 179-184, 1991. 